\title{
Um Objeto de Aprendizagem sobre medidas de prevenção na Internet: conscientização do usuário
}

\author{
Núbia dos S. R. S. dos Santos ${ }^{1}$, Clevi Elena Rapkiewicz ${ }^{2}$, Leandro Krug Wives ${ }^{3}$, \\ José Valdeni de Lima ${ }^{4}$ \\ ${ }^{1}$ UFF - Universidade Federal Fluminense/UFF- Niterói - RJ - Brasil \\ ${ }^{2}$ UFRGS - Escola Técnica/IFRS - Porto Alegre - RS - Brasil \\ ${ }^{34}$ PPGC - Programa de Pós-Graduação em Computação - Universidade Federal do Rio \\ Grande do Sul/UFRGS Porto Alegre - RS - Brasil \\ ${ }^{4}$ PPGIE - Programa de Pós-Graduação em Informática na Educação- Universidade \\ Federal do Rio Grande do Sul/UFRGS Porto Alegre - RS - Brasil
}

nubia@sti.uff.br,clevi.rapkiewicz@ufrgs.br,\{wives, valdeni\}@inf.ufrgs.br

\begin{abstract}
The Internet has brought great benefits for education mainly for the easy distribution and access to information. However, some risks related to user safety also emerged, demanding more attention and care to use the resources available on the Internet. This article highlights the need for awareness, using educational content, of existing risks on the Internet. In this context, we developed a Learning Object about this topic. This object was used in the classroom by students and then we could compare the knowledge and concerns of students in relation to the risk on the Internet, before and after using the Learning Object.
\end{abstract}

Resumo. A Internet trouxe muitos benefícios para a educação, principalmente pela facilidade de distribuição e acesso às informações. No entanto, alguns riscos relacionados à segurança do usuário também surgiram, demandando mais atenção e cuidado ao utilizar os recursos disponíveis na Internet. Este artigo destaca a necessidade de conscientização, através de conteúdos educacionais, em relação aos riscos existentes na Internet. Nesse contexto, foi desenvolvido um Objeto de Aprendizagem(OA) sobre essa temática. O OA foi utilizado em sala de aula pelos alunos e, em seguida, pôde-se comparar o conhecimento e receios dos alunos em relação aos riscos existentes na Internet, antes e após o estudo do Objeto de Aprendizagem.

\section{Introdução}

A Internet trouxe grandes benefícios para a educação principalmente pela facilidade de distribuição e acesso às informações. No entanto, alguns riscos relacionados à segurança do usuário também surgiram, demandando mais atenção e cuidado ao utilizar os recursos disponíveis na Internet. A facilidade de propagação e acesso às informações requer precaução do usuário para distinguir as fontes seguras das maliciosas, que podem ser utilizadas para obter dados sigilosos dos usuários. De acordo com Canongia e Junior (2009), é preciso aumentar a formação de recursos humanos especializados em segurança cibernética e em áreas correlatas, em todos os níveis, desde a formação básica, 
passando pela técnica, e alcançando até o nível da pós-graduação. Além disso, para eles (ibdem), a conscientização deve ser iniciada desde o ensino fundamental, criando uma cultura orientada a esta abordagem, uma vez que a iniciação digital ocorre cada vez mais cedo, em idades mais precoces. Segundo Marciano e Marques (2006), a proliferação da Internet e de redes corporativas, ao mesmo tempo que introduz formas de fácil e rápida utilização dos recursos computacionais, expõe ainda mais a fragilidade e os riscos a que estão expostos os usuários. Nesse contexto, considerando a relevância do tema no ensino, este artigo apresenta os resultados da aplicação de um Objeto de Aprendizagem (OA) sobre medidas de prevenção na Web para alunos de um curso na modalidade Educação de Jovens e Adultos - EJA. O artigo está estruturado da seguinte forma: a seção 2 apresenta o OA sobre Prevenção na Internet, a seção 3 apresenta o experimento realizado com alunos do EJA e discute alguns resultados. Por fim, a seção 4 apresenta as considerações finais.

\section{Objeto de Aprendizagem sobre prevenção na Web}

Para apresentar os riscos existentes na Internet e as respectivas medidas de prevenção foi desenvolvido um Objeto de Aprendizagem (OA), denominado Prevenção na Internet. Além dos conceitos de malware, spam e invasões, foi abordado o assunto Engenharia Social, termo ainda desconhecido por grande parte dos alunos. Vale ressaltar que tais assuntos devem ser discutidos com mais frequência nos cursos presenciais, e a distância, de modo a conscientizar os usuários sobre as fraudes e falsas mensagens distribuídas na Internet. Além disso, o usuário deve também atentar para o risco dos falsos perfis os quais também são criados com o intuito de obter informações através de engenharia social (Santos, Bezerra e Alturas, 2010). De acordo com a Cartilha de Segurança para Internet (2012), entende-se por Engenharia Social a técnica por meio da qual uma pessoa procura persuadir outra a executar determinadas ações. A expansão dos recursos disponibilizados na Internet, inclusive nas redes sociais, requer que o usuário tenha algumas precauções em relação às informações que compartilha, assim como analisar as informações compartilhadas pelos demais usuários.

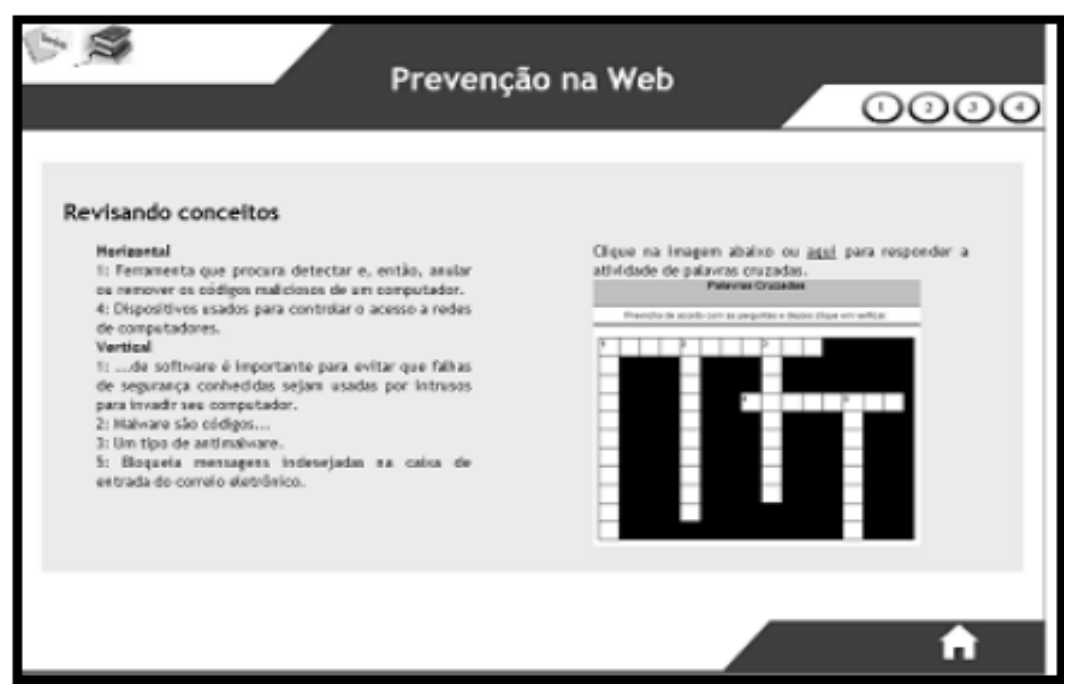

Figura 1. OA Prevenção na Internet 
O OA Prevenção na Internet (Santos, Lima e Wives, 2012), apresentado na Figura 1, foi desenvolvido em HTML5 e disponibilizado no Ambiente Virtual de Aprendizagem Moodle, um sistema open source para gerenciamento de cursos. O OA apresenta a definição de cada risco, as respectivas medidas de prevenção, alguns exemplos, atividades e exercícios. O OA foi aplicado na turma de Ensino Médio, na modalidade EJA, com objetivo de propor uma reflexão acerca dos riscos existentes ao usar a Internet e os respectivos meios e ferramentas de prevenção.

\section{Experimento com o Objeto de Aprendizagem}

A metodologia utilizada envolveu duas etapas. Na primeira etapa os alunos responderam um questionário, com questões discursivas, sobre Segurança na Internet e relataram suas preocupações ao utilizá-la. Na segunda etapa, após explorar o OA Prevenção na Internet, os alunos responderam outro questionário sobre Segurança na Internet e relataram suas preocupações. O conceito de Engenharia Social foi abordado e verificouse, na primeira etapa, que os alunos não conheciam essa técnica, respondendo de forma equivocada. A partir das respostas dos alunos foi utilizada uma ferramenta para criação de nuvens de palavras, ou seja, uma apresentação gráfica relacionada à ocorrência de palavras no texto. A questão sobre as preocupações com segurança e assuntos correlatos, aplicada na primeira etapa - antes da utilização do OA - resultou na nuvem apresentada na Figura 2. Observa-se que há manifestação de medo, preocupação, mas com pouca presença de palavras específicas relacionadas ao tema e respostas aos riscos - medidas de prevenção.

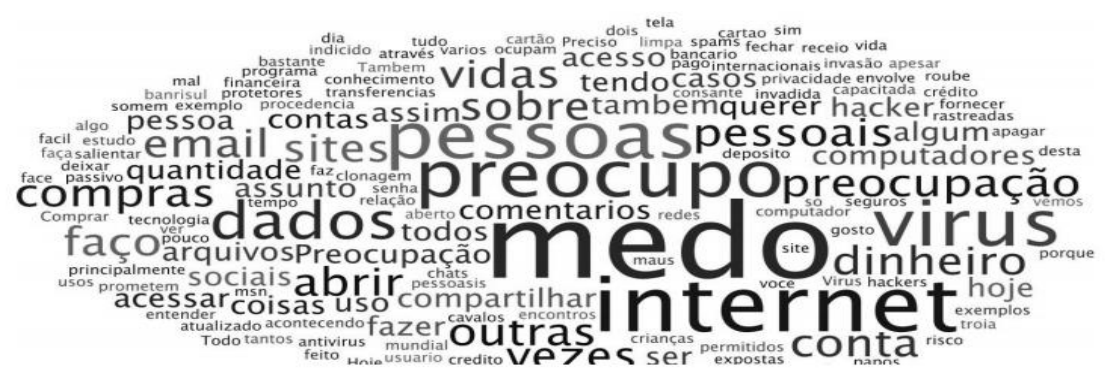

Figura 2. Nuvem de palavras - Primeira etapa

A nuvem apresentada na Figura 3 retrata o resultado obtido da mesma questão relativa às preocupações, porém após o uso do Objeto de Aprendizagem. Observa-se a presença de palavras mais específicas como engenharia social, antivírus, cuidado, segurança, entre outras.

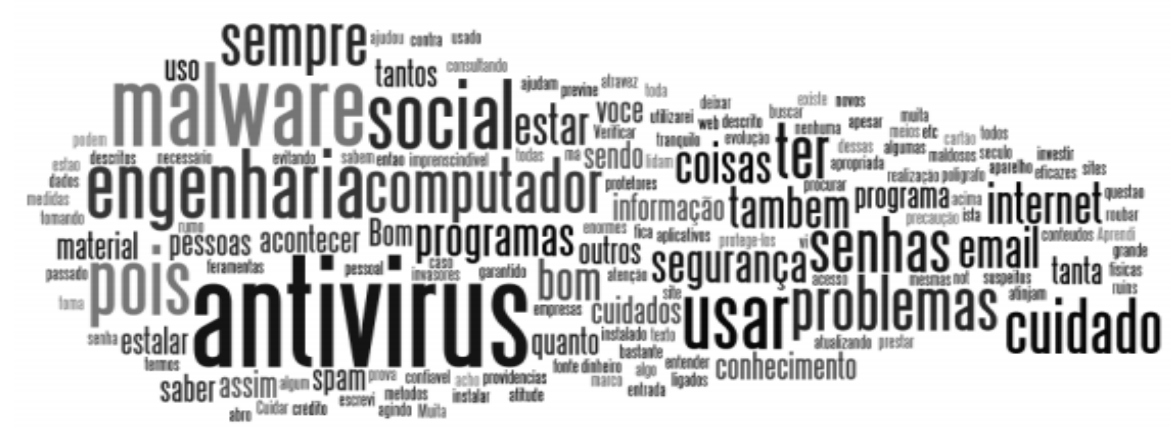

Figura 3. Nuvem de palavras - Segunda etapa 
O resultado obtido após a utilização do OA evidenciou que os alunos manifestaram mais conhecimento em relação aos riscos disponíveis na Internet, bem como os recursos e medidas de prevenção. Em relação ao conceito de engenharia social as respostas dos alunos na segunda etapa evidenciaram que ocorreu a compreensão do conceito. Além disso, foram aplicados dois questionários, com sete questões objetivas, sobre os riscos e medidas de prevenção: um antes ( $1^{\mathrm{a}}$ etapa) e outro após a utilização do OA ( $2^{a}$ etapa). A partir das respostas dos alunos (quinze alunos) verificou-se que a média de acertos no questionário 1 foi $29 \%$ enquanto no questionário 2 a média de acertos dos alunos foi $81 \%$. Esses resultados evidenciam um melhor desempenho dos alunos após o estudo realizado com o OA.

\section{Considerações finais}

Este artigo abordou a relevância de elaborar conteúdos educacionais para conscientização dos usuários sobre os riscos e ameaças existentes na Internet, apresentando medidas e dicas de segurança. Além disso, percebe-se que o uso de recursos de Tecnologias de Informação e Comunicação tem aumentando na educação, mas não necessariamente temas como segurança e engenharia social são tratados. No caso de uma população típica de imigrantes digitais, como é o caso dos alunos na modalidade EJA, essa preocupação torna-se ainda maior, pois se trata de público não muito familiarizado com uso de TICs. O experimento realizado com a turma de EJA no Colégio de Aplicação/UFRGS mostrou a pertinência dessa preocupação e a motivação dos alunos para a temática. A análise da percepção e o resultado obtido com a aplicação dos questionários, após o uso do OA, evidencia uma mudança positiva em relação à atenção, precaução e conscientização acerca dos riscos do uso da Internet.

\section{Agradecimento}

Agradecimento à Profa Taisy Weber pela contribuição referente ao conteúdo do Objeto de Aprendizagem.

\section{Referências}

Canongia, C.; Junior, R.M. (2009) Segurança cibernética: o desafio da nova Sociedade da Informação, Parc. Estrat. Brasília-DF, v. 14, n. 29, p. 21-46

Cartilha de Segurança para Internet (2012) versão 4.0 / CERT.br - São Paulo: Comitê Gestor da Internet no Brasil

Marciano, J.L.; Marques, M.L. (2006) O enfoque social da segurança da informação, Inf., Brasília, v. 35, n. 3, p. 89-98, set./dez. 2006, Disponível em: http://www.scielo.br/pdf/ci/v35n3/v35n3a09, Acesso em: Maio de 2014.

Santos, V.S.; Bezerra, E.P.; Alturas, B. (2010), Análise de mecanismos de controle de acesso nas redes sociais, Rev. Portuguesa e Brasileira de Gestão[online]. vol.9, n.3, pp. 50-60. Disponível em: http://www.scielo.oces.mctes.pt/scielo.php?pid=S164544642010000200006\&script=sci_arttext, Acesso: Maio de 2014.

Santos, N.S.R.S.; Lima, J. V.; Wives, L. K.(2012) Integração de recursos para acesso aos Objetos de Aprendizagem Multimodais. RENOTE. Revista Novas Tecnologias na Educação, v. 10, p. 1-10 